\title{
Testicular mixed germ cell tumors: a morphological and immunohistochemical study using stem cell markers, OCT3/4, SOX2 and GDF3, with emphasis on morphologically difficult-to-classify areas
}

\author{
Anuradha Gopalan ${ }^{1}$, Deepti Dhall ${ }^{1}$, Semra Olgac ${ }^{1}$, Samson W Fine ${ }^{1}$, James E Korkola ${ }^{2}$, \\ Jane Houldsworth ${ }^{2}$, Raju S Chaganti ${ }^{2}$, George J Bosl ${ }^{3}$, Victor E Reuter ${ }^{1}$ and Satish K Tickoo ${ }^{1}$ \\ ${ }^{1}$ Department of Pathology, Memorial Sloan Kettering Cancer Center, New York, NY, USA; ${ }^{2}$ Cell Biology \\ Program, Memorial Sloan Kettering Cancer Center, New York, NY, USA and ${ }^{3}$ Department of Internal \\ Medicine, Memorial Sloan Kettering Cancer Center, New York, NY, USA
}

\begin{abstract}
Stem cell markers, ОСT3/4, and more recently SOX2 and growth differentiation factor 3 (GDF3), have been reported to be expressed variably in germ cell tumors. We investigated the immunohistochemical expression of these markers in different testicular germ cell tumors, and their utility in the differential diagnosis of morphologically difficult-to-classify components of these tumors. A total of $\mathbf{5 0}$ mixed testicular germ cell tumors, 43 also containing difficult-to-classify areas, were studied. In these areas, multiple morphological parameters were noted, and high-grade nuclear details similar to typical embryonal carcinoma were considered 'embryonal carcinoma-like high-grade'. Immunohistochemical staining for OCT3/4, c-kit, CD30, SOX2, and GDF3 was performed and graded in each component as 0 , negative; $1+, 1-25 \% ; 2+, 26-50 \%$; and $3+,>50 \%$ positive staining cells. The different components identified in these tumors were seminoma (8), embryonal carcinoma (50), yolk sac tumor (40), teratoma (40), choriocarcinoma (3) and intra-tubular germ cell neoplasia, unclassified (35). By immunohistochemistry, the staining patterns were OCT3/4 $-3+$, all seminomas, embryonal carcinomas and intra-tubular germ cell neoplasia; SOX2 -3+, all embryonal carcinomas and -2 to $3+, 11 / 14(79 \%)$ primitive neuroectodermal components in immature teratomas; GDF3 -2 to $3+$, all yolk sac tumors, seminomas and intra-tubular germ cell neoplasia and 1 to $2+, 40 / 50$ embryonal carcinomas. A total of $34 / 43(79 \%)$ of difficult-to-classify areas stained $3+$ for OCT3/4, CD30, and SOX2, similar to embryonal carcinoma. Among these areas, only 'embryonal carcinoma-like high-grade' nuclear details were significantly associated with such an immunophenotype. Thus, soX2 is expressed in embryonal carcinoma and primitive neuroectoderm of teratoma, and unlike OCT3/4, not in intra-tubular germ cell neoplasia and seminoma. Therefore, it may be useful in the distinction of seminoma from embryonal carcinoma, and potentially in diagnosing early carcinomatous differentiation in seminoma. GDF3 positivity, in the absence of OCT3/4 and CD30, combined with morphological features, is helpful in the diagnosis of yolk sac tumor. 'Embryonal carcinoma-like high-grade' nuclear details are the most important morphological criterion for the diagnosis of embryonal carcinoma in difficult-to-classify areas.
\end{abstract}

Modern Pathology (2009) 22, 1066-1074; doi:10.1038/modpathol.2009.66; published online 24 April 2009

Keywords: OCT3/4; SOX2; GDF3; stem cell; testis; germ cell tumors

Germ cell tumors comprise a morphologically heterogeneous but histogenetically related popula-

Correspondence: Dr SK Tickoo, Department of Pathology, Memorial Sloan Kettering Cancer Center, 1275 York Avenue, New York, NY 10065, USA.

E-mail: tickoos@mskcc.org

Received 25 January 2009; revised 25 March 2009; accepted 29 March 2009; published online 24 April 2009 tion of tumors. Pathologists classify germ cell tumors on the basis of the cytomorphological differences observed in them. However, it is not uncommon to encounter areas within a tumor that are difficult to classify because of overlapping morphological features or poor tissue preservation. Examples of the former may include (1) areas with architecture considered typical of yolk sac tumor (eg, glandular, early secretory endometrium-like), 
but with markedly atypical cytological features; (2) atypical areas within or adjacent to seminoma that suggest an early transformation to embryonal carcinoma; and (3) the interface of embryonal carcinoma and solid yolk sac tumor with cytological features unlike the typical yolk sac tumor. Appropriate classification of germ cell tumor components is essential as biological behavior and therapeutic decisions are dependent on it. For example, the predominance of embryonal carcinoma component in a stage I non-seminomatous tumor requires additional therapy after orchiectomy, as it is commonly associated with high risk of failure on surveillance alone. ${ }^{1-3}$ Similarly, tumors showing early carcinomatous differentiation in seminoma may be managed more aggressively than pure seminomas at some institutions. ${ }^{4}$

Multiple studies have shown that different subtypes of germ cell tumors differentially express several genes that are required for the maintenance of 'stemness' of embryonic stem cells. ${ }^{5-8}$ An earlier cDNA microarray study that was carried out at our institution showed high expression levels of a cadre of such genes like $S O X 2$, growth differentiation factor 3 (GDF3), TDGF, EBAF and FGF4 in embryonal carcinoma, but not in seminoma. ${ }^{9}$ On the other hand, both seminoma and embryonal carcinoma cooverexpressed STELLA, NANOG and OCT4, which are some of the other genes important for stem cell maintenance. These findings support the earlier reported observations that genes implicated in stem cell function are expressed to a greater extent in embryonal carcinoma than in seminoma. ${ }^{10,11}$ Several of these stem cell genes, but not SOX2 and OCT4, map to the 'Stem Cell Cluster Region,' 12p13.31, a region gained in germ cell tumors either in the form of an isochromosome $12 \mathrm{p}(80 \%)$ or less frequently, as excess $12 p$ genetic material in derivative chromosomes. ${ }^{9,12}$

SOX2 (SRY-related HMGbox2) and OCT3/4 transcription factors increase the transcription of several genes required for the maintenance of the 'stemness' of cells. Increased levels of SOX2-OCT3/4 maintain the pluripotent state of germ cells, and a decrease in their levels leads to differentiation. ${ }^{13-15}$ In addition, SOX2 is also known to regulate the pluripotency of neural stem cells. ${ }^{16,17}$ OCT3/4 is currently used widely in the differential diagnosis of germ cell tumors, both at gonadal and extragonadal sites. ${ }^{8,18}$ SOX2 has also recently been shown to be helpful in this differential diagnosis. ${ }^{8,9}$ GDF3, a TGF- $\hat{a}$ superfamily ligand, which is postulated to have a role in skeletal organogenesis in addition to contributing to the maintenance of stem cell pluripotency, is a transcription factor that localizes to 'Stem Cell Cluster Region'. ${ }^{9,19}$ GDF3 is overexpressed in human embryonic stem cell, ${ }^{19}$ and has now also been shown to be overexpressed in testicular embryonal carcinoma at the molecular level. ${ }^{9}$

In view of their reported differential expression in phenotypically distinct germ cell tumor subtypes at the molecular level, we investigated the immunohistochemical expression of these relatively recently identified stem cell markers, SOX2 and GDF3, in testicular germ cell tumors. We also investigated the utility of these and other more established markers (OCT3/4, CD30 and c-kit) in the differential diagnosis of areas otherwise morphologically 'difficultto-classify', particularly in the distinction between yolk sac tumor and embryonal carcinoma.

\section{Materials and methods}

The study was approved by the Institutional Review Board and the Human Biospecimen Utilization Committee. A total of 50 testicular germ cell tumors were investigated. Areas of classical embryonal carcinoma, yolk sac tumor, mature teratoma, immature teratoma, choriocarcinoma and seminoma, as well as intra-tubular germ cell neoplasia, unclassified (IGCNU), were delineated on the H\&E sections. Of these tumors, 43 also contained areas that on a morphological basis were difficult to classify as either embryonal carcinoma or yolk sac tumor. Most of these difficult-to-classify areas had solid architecture, with variable cytomorphological features (as detailed later). Four cases also showed glandular/papillary architecture with sub-nuclear vacuoles (yolk sac tumor-like), but with nuclear pleomorphism and nuclear overlap that did not fit in with the classical description of the cytological features of yolk sac tumor. ${ }^{20}$ One representative block was chosen from each tumor, so that it also contained difficult-to-classify areas whenever possible, and immunohistochemical staining for OCT3/ 4, SOX2, GDF3, c-kit and CD30 was performed as detailed (Table 1).

Immunoreactivity with each of the antibodies was graded semi-quantitatively in each component of

Table 1 Details of the antibodies used

\begin{tabular}{llcl}
\hline Antibody & Particulars/source & Dilution & Antigen retrieval \\
\hline SOX2 & Mouse monoclonal, clone 245610, R\&D Systems, Minneapolis, MN, USA & $1: 100$ & None \\
GDF3 & Goat polyclonal, A-20, Santa Cruz Biotechnology, Santa Cruz, CA, USA & $1: 100$ & Trypsin for 30 min at 37 C \\
OCT3/4 & Goat polyclonal; C-20, Santa Cruz Biotechnology, Santa Cruz, CA, USA & $1: 4000$ & Microwave 30 min, EDTA, pH 8 \\
C-KIT & Rabbit polyclonal; Dako, Carpinteria, CA, USA & $1: 800$ & Steam 30 min, Citrate buffer, pH 6 \\
CD30 & Mouse monoclonal, clone Ber-H2 ${ }^{3}$; Dako, Carpinteria, CA, USA & $1: 50$ & Steam 30 min, Citrate buffer, pH 6
\end{tabular}


germ cell tumors from 0 to $3+(0$, negative; +1 , $1-25 \%$ positive staining cells; $+2,26-50 \%$ positive staining cells; and $+3,>50 \%$ positive staining cells). Any distinct nuclear (SOX2 and OCT3/4) or cytoplasmic/membranous (CD30, GDF3 and c-kit) brown staining was considered a positive result.

In difficult-to-classify areas, in addition to the earlier mentioned architectural features (see above), the following cytomorphological features were assessed: (1) nuclear features; (2) nuclear overlap; (3) definition (distinctness) of cell borders; and (4) karyorrhexis. For the nuclear features, shape, size, pleomorphism, chromatin pattern, nuclear membrane irregularities or nucleolar prominence similar to those in the classical embryonal carcinoma in the same section were considered to be 'embryonal carcinoma-like high-grade' for the purpose of this study. Immunoreactivity in these areas for each of the 5 antibodies was also graded as 0 to +3 . Statistical methods (Fisher's exact test) were used to observe associations between any of the above morphological features and combined positive staining for OCT3/4, SOX2 and CD30.

\section{Results}

The immunohistochemistry results in morphologically classical areas of different germ cell tumor components are summarized in Table 2.

\section{OCT3/4}

Diffuse and intense nuclear staining was observed in embryonal carcinoma (50/50) (Figures $1 \mathrm{a}$ and b), seminoma (8/8) (Figures 2a and b) and IGCNU (35/ 35) components in all tumors. No immunoreactivity was observed in any of the yolk sac tumor, mature teratoma, immature teratoma or choriocarcinoma components.

\section{c-kit}

The c-kit expression was strong and diffuse $(3+)$ in all seminomas and IGCNU. However, $6 \%$ of embryonal carcinomas and $35 \%$ of yolk sac tumors also showed rare cells $(1+)$ to be positive.

\section{CD30}

A total of $49 / 50$ (98\%) embryonal carcinomas expressed $3+$ positivity with CD30 and no staining was present in any other components. However, the intensity of staining in embryonal carcinoma was quite variable, requiring an evaluation at high magnification $(\times 40)$ in some cases.

\section{SOX2}

The location of staining was nuclear. Embryonal carcinoma components in all $50(100 \%)$ tumors studied showed $3+$ positivity, with moderate-tointense staining (Figure 1c). The only other component that showed reactivity was the primitive neuroectodermal component in 11 of 14 (79\%) immature teratomas. In each of these positive staining foci the staining varied from $2+$ to $3+$ (Figures 2d-f). Yolk sac tumor, seminoma, mature teratoma, choriocarcinoma and IGCNU were uniformly negative, as were all the non-neoplastic parenchymal and stromal structures.

\section{GDF3}

The location of staining was cytoplasmic and different components showed variations in the staining grades. All seminomas and IGCNU (100\%) were $3+$ immunoreactive. In all three choriocarcinoma components, the cytotrophoblastic parts showed $3+$ positivity, whereas the syncytiotrophoblastic component was either completely nonreactive or showed very weak, focal positivity. All $40(100 \%)$ yolk sac tumors showed relatively diffuse $(2+$ or $3+)$ (Figure 1d) and strong immunoreactivity, whereas 40/50 (80\%) embryonal carcinomas were also positive. However, the immunoreactivity in yolk sac tumor was always more diffuse and stronger than in the EC components (1 to $2+)$.

Table 2 Immunohistochemical marker profile of various germ cell tumor components

\begin{tabular}{|c|c|c|c|c|c|}
\hline Tumor component (No.) & $\begin{array}{c}\text { OCT3/4 no. (\%) } \\
\text { (grade) }\end{array}$ & $\begin{array}{l}\text { c-kit no. (\%) } \\
\text { (grade) }\end{array}$ & $\begin{array}{l}\text { CD30 no. (\%) } \\
\text { (grade) }\end{array}$ & $\begin{array}{l}\text { SOX2 no. (\%) } \\
\text { (grade) }\end{array}$ & $\begin{array}{l}\text { GDF3 no. (\%) } \\
\text { (grade) }\end{array}$ \\
\hline Embryonal carcinoma (50) & 50 (100) (all 3+) & $3(6)(\text { all } 1+)^{a}$ & 49(98) (all 3+) & 50 (100) (all 3+) & $40(80)(1$ or $2+)$ \\
\hline Yolk sac tumor $(40)$ & 0 & $14(35)(\text { all } 1+)^{\mathrm{a}}$ & 0 & 0 & $40(100)(2$ or $3+)$ \\
\hline Seminoma (8) & 8 (100) (all 3+) & 8 (100) (all 3+) & 0 & 0 & $8(100)($ all $3+)$ \\
\hline Mature teratoma (26) & 0 & 0 & 0 & 0 & 26 (100) (all 3+) \\
\hline Immature teratoma (14) & 0 & 0 & 0 & $11(79)^{\mathrm{b}}(2-3+)$ & 0 \\
\hline Choriocarcinoma (3) & 0 & 0 & 0 & 0 & $3(100)^{\mathrm{c}}$ (all 3+) \\
\hline IGCNU (35) & 35 (100) (all 3+) & 35 (100) (all 3+) & 0 & 0 & 35 (100) (all 3+) \\
\hline
\end{tabular}

IGCNU, intratubular germ cell neoplasia.

${ }^{\mathrm{a}}$ Rare cells positive.

${ }^{\mathrm{b}}$ Only in the primitive neuroectodermal component of immature teratoma.

${ }^{\mathrm{C}}$ Only in cytotrophoblast. 

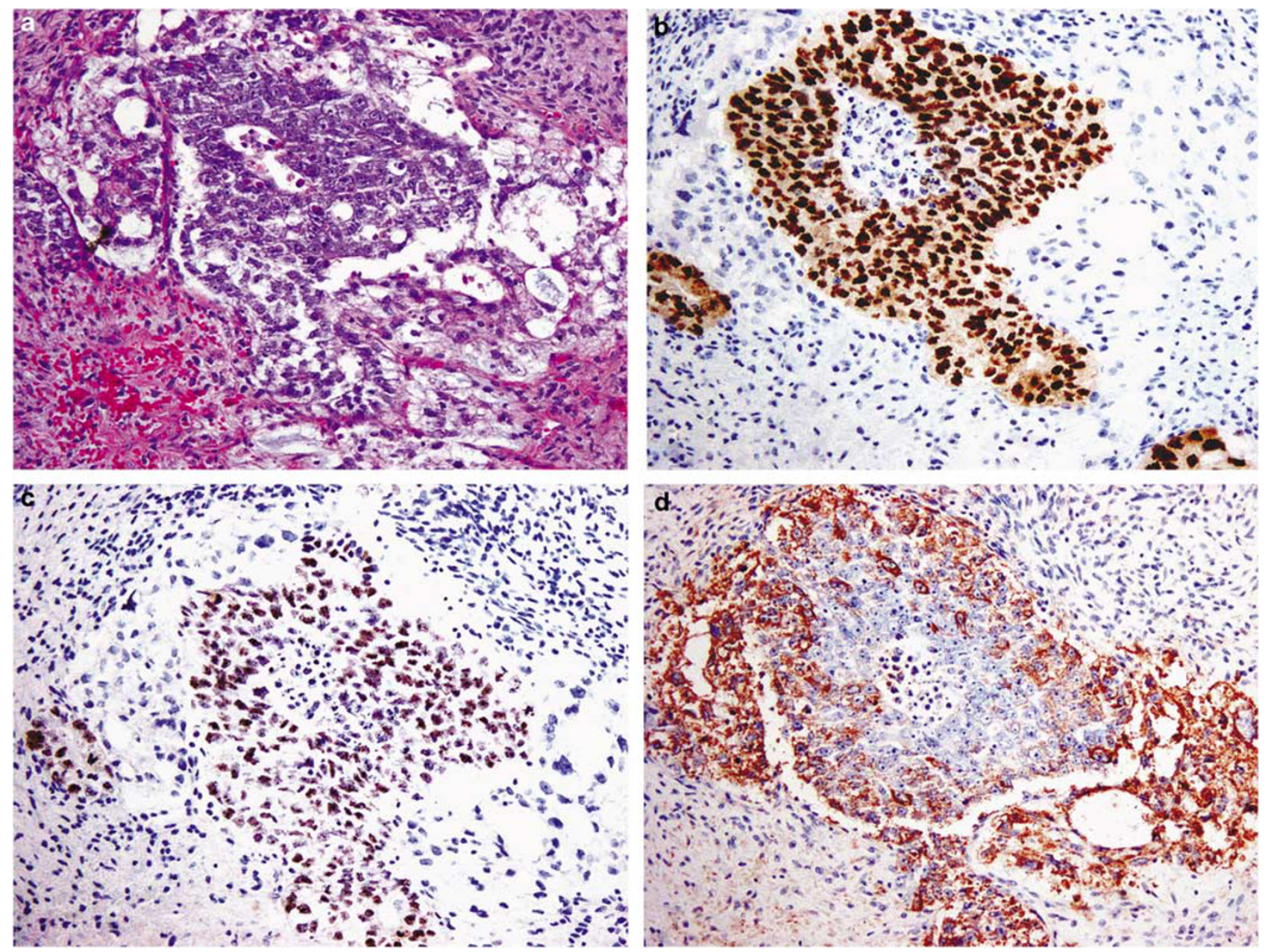

Figure 1 Mixed germ cell tumor with embryonal carcinoma and yolk sac tumor components (a). The $3+$ positivity in embryonal carcinoma for OCT3/4 (b) and SOX2 (c) is noted. The yolk sac component shows $3+$ immunoreactivity for GDF3, whereas there is a more focal positivity in embryonal carcinoma (d).

As all embryonal carcinomas (except one that was CD30 negative) and no other germ cell tumor component showed a OCT3/4+, CD30 + and SOX2 + immunophenotype, this was considered diagnostic of embryonal carcinoma in the evaluation of difficult-to-classify areas. Table 3 shows the correlationship between different morphological features in these areas and OCT3/4+, CD30 + and SOX $2+$ (embryonal carcinoma-like) immunophenotype. Of all the morphological features evaluated, only the 'embryonal carcinoma-like high-grade' nuclear features in these areas showed a significant correlationship with an embryonal carcinoma immunophenotype $(P=0.0001)$ (Figure 3$)$.

\section{Discussion}

OCT3/4 and SOX2 are transcription factors expressed in the embryonic stem cell, with SOX2 also being expressed in neural stem cells. ${ }^{11,13,14,16}$ Through a cooperative interaction, SOX2 and OCT3/4 drive pluripotent-specific expression of a number of genes, including SOX2, OCT3/4 and $N A N O G$, into a feedback autoregulatory loop. Increased levels of SOX2-OCT3/4 maintain the pluripotent state, whereas a decrease in their levels leads to differentiation. ${ }^{14,15}$ GDF3, a TGF- $\beta$ superfamily ligand, is localized to 'stem cell cluster region,' 12p13.31, a region which is gained in germ cell tumors. ${ }^{9,12,19}$

Our observation of OCT3/4+, SOX2 + and GDF3 + phenotype in the embryonal carcinoma component of germ cell tumors on immunohistochemical staining supports the belief that embryonal carcinoma is ontologically closer to the embryonic stem cell, whereas seminoma, with OCT3/4+, SOX - and GDF3 + immunoprofile (both in the mixed germ cell tumors, as here and pure classical seminomasdata not shown) more closely resembles primordial germ cell. ${ }^{21,22}$ From the stand point of pathogenesis, the more primitive immunophenotype of embryonal carcinoma compared with that of seminoma and IGCNU raises some interesting issues. The current prevalent belief is that most, if not all, nonseminomatous testicular germ cell tumors arise from 

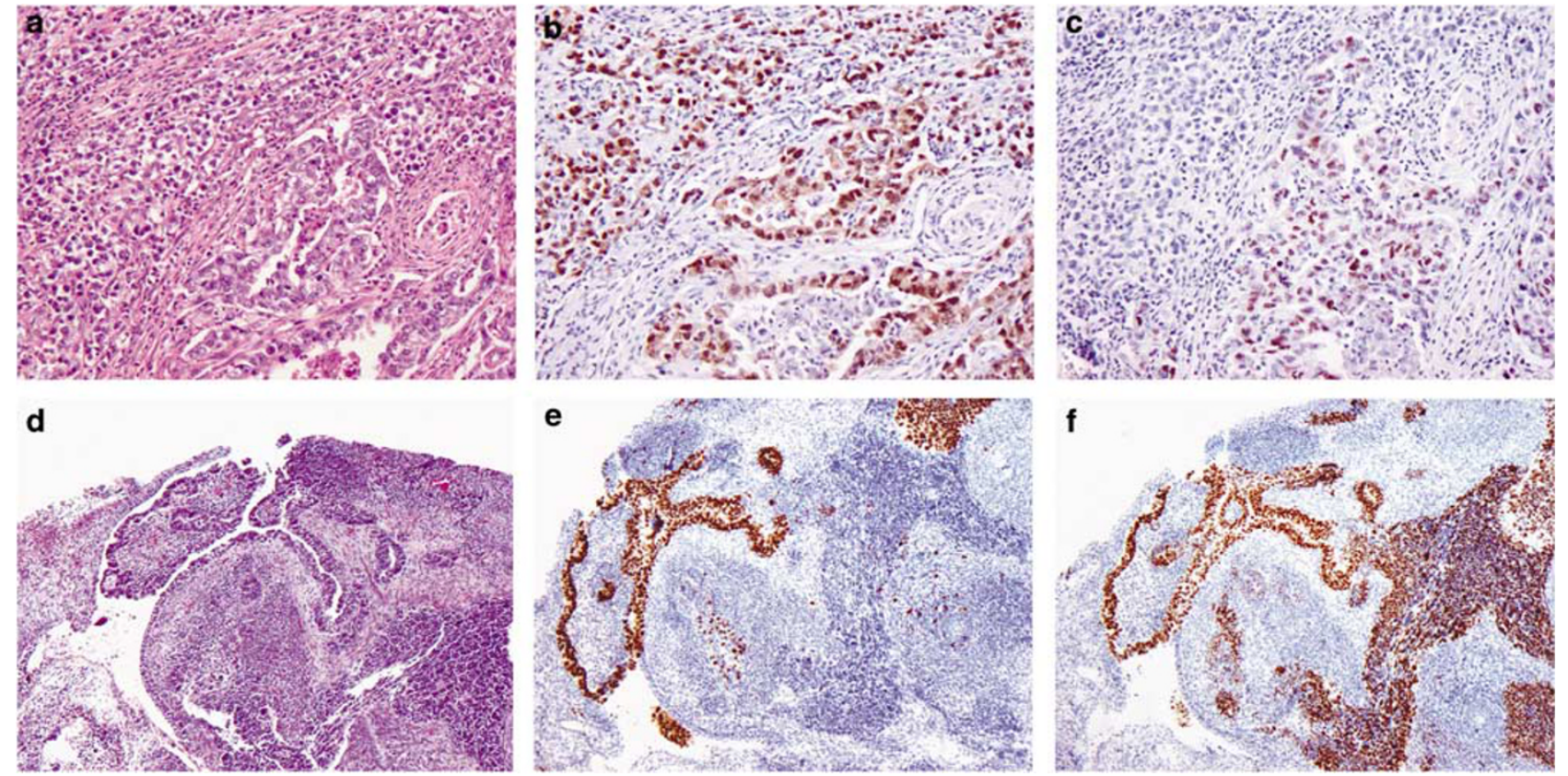

Figure 2 Both the seminoma (on left side of the figure) and embryonal carcinoma components in the tumor (a) showing $3+$ immunoreactivity for OCT3/4 (b). SOX2 is only positive in the embryonal carcinoma component (c). In another tumor showing embryonal carcinoma and primitive neuroectodermal morphologies (d), OCT3/4 stains the embryonal carcinoma part (e), whereas SOX2 shows diffuse immunoreactivity both in the embryonal carcinoma and in the primitive neuroectodermal components (f).

Table 3 Immunohistochemical staining pattern based on morphological criteria in difficult-to-classify areas

\begin{tabular}{|c|c|c|c|}
\hline Morphological features & & OCT3/4+, CD30+, SOX2+ & $\mathrm{P}$-value \\
\hline \multirow{2}{*}{ 'Embryonal carcinoma-like high-grade' nuclear features } & Yes $(31)^{\mathrm{a}}$ & $29(94 \%)$ & 0.0001 \\
\hline & No (12) & $4(33 \%)$ & \\
\hline \multirow{2}{*}{ Nuclear overlap } & Present $(4)^{\mathrm{a}}$ & $2(50 \%)$ & 0.2263 \\
\hline & Absent (39) & $31(79 \%)$ & \\
\hline \multirow[t]{2}{*}{ Karyorrhexis index } & High $(10)^{\mathrm{a}}$ & $7(70 \%)$ & 0.6741 \\
\hline & Not high (33) & $26(79 \%)$ & \\
\hline \multirow[t]{2}{*}{ Distinct cell borders } & Present (39) & $30(77 \%)$ & 1.000 \\
\hline & Absent $(4)^{a}$ & $3(75 \%)$ & \\
\hline
\end{tabular}

${ }^{\text {a }}$ Similar to that in morphologically characteristic areas of embryonal carcinoma in the same slide.

seminoma, and that all germ cell tumors are derived from IGCNU. If IGCNU and seminoma are indeed the precursors of most other testicular germ cell tumors-evidence for which abounds in the literature ${ }^{23-27}$ - then compared with seminoma, the more primitive phenotype of embryonal carcinoma can be best explained by the process of 'nuclear reprogramming'. It has been shown that primordial germ cells, and even more differentiated embryonic or adult fibroblasts, in the presence of certain stem cell factors and in some specific cell culture conditions, can be 'reprogrammed' into an embryonic stem celllike state. ${ }^{28,29}$ The alternate possibility that embryonal carcinoma, being similar to the most primitive of the stem cells, is the precursor of all other germ cell tumors, including seminoma, cannot be substantiated in view of the data that are currently available. $^{23-27}$
Although embryonal carcinoma resembles the embryonic stem cell at the molecular ${ }^{9-12,21,22}$ and immunohistochemical levels, it differs significantly from the embryonic stem cell in that it also expresses cytokeratins. In the development and differentiation of the embryonic stem cell, keratins begin to appear at the level of early primitive ectoderm or ectoderm-like cell, a derivative of the inner cell mass. At the same time, primitive ectoderm-like cells have also been shown to be embryonic stem cell-like in their 'stemness', expressing OCT3/4 levels equivalent to those seen in the embryonic stem cell. ${ }^{30}$ Their 'stemness' is also supported by the ability of primitive ectoderm to give rise to germ cells. ${ }^{31}$ Thus, primitive ectoderm or ectoderm-like cell formation by itself, is not considered to be a terminal differentiation event, but is believed to reflect the ability of pluripotent cells to 

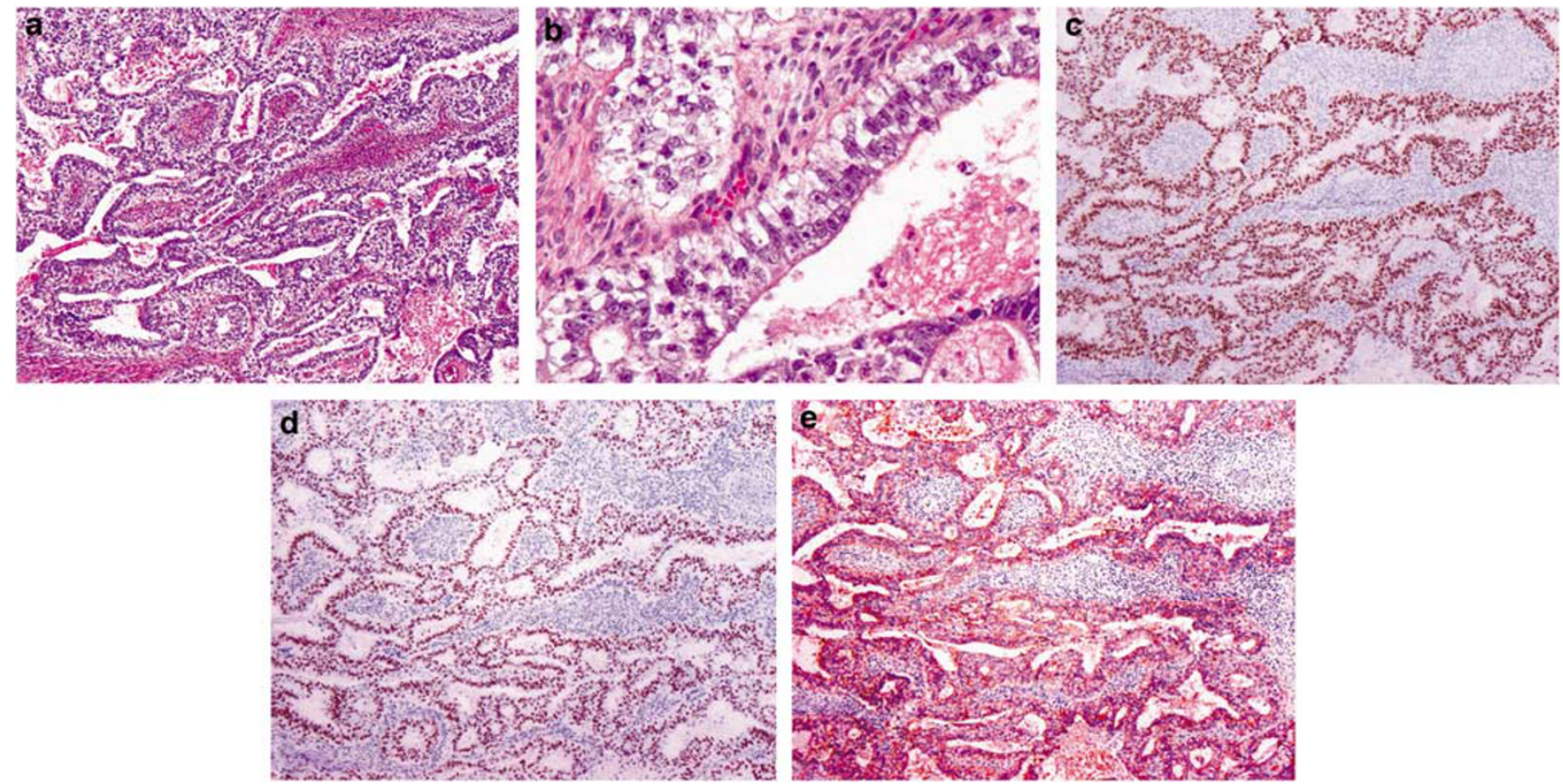

Figure 3 Difficult-to-classify area in a mixed germ cell tumor. Glandular architecture with prominent sub-nuclear vacuoles suggests the diagnosis of yolk sac tumor (a). However, a higher magnification shows high-grade nuclear features, with distinct cell borders and without significant nuclear overlap or apoptosis (b). Immunostains show $3+$ positivity for OCT3/4 (c), SOX2 (d) and CD30 (e), supporting the diagnosis of embryonal carcinoma.

adopt distinct cell states in response to specific factors. On the basis of these facts, it appears that embryonal carcinoma cells are more similar to somewhat more 'differentiated' primitive ectoderm or ectoderm-like cell rather than to the generally believed embryonic stem cell. In view of these observations, we propose a pathogenesis model of germ cell tumors slightly modified from what is suggested currently (Figure 4).

A number of our findings are also highly relevant from a clinicopathologic perspective. First, as OCT3/4 + , CD30 + and SOX2 + immunophenotype was found to be specific for embryonal carcinoma, we applied this phenotype in the decision-making algorithm for embryonal carcinoma in areas that were difficult to assign morphologically to yolk sac tumor or embryonal carcinoma. We found that only 'embryonal carcinoma-like high-grade' nuclear features showed a significant association with the immunoprofile characteristic of embryonal carcinoma. From this observation, we conclude that 'embryonal carcinoma-like high-grade' nuclear features alone should be the defining features of embryonal carcinoma, at least in difficult-to-classify areas, and that other features, such as architecture, lack of nuclear overlap, prominent karyorrhexis or prominent mitotic activity do not make or exclude a diagnosis of embryonal carcinoma.

Furthermore, SOX2 expression in embryonal carcinoma and not in seminoma can be used not only in differentiating seminoma from embryonal carcinoma, but also potentially in detecting early carcinomatous differentiation in seminoma.
Although CD30 and cytokeratin expressions are used typically in this distinction, in our experience, CD30 suffers from an occasional very weak expression in the otherwise classical embryonal carcinoma. Moreover, CD30 expression tends to be lost in post-chemotherapy embryonal carcinoma and is reportedly absent in up to $65 \%$ of treated embryonal carcinoma at metastatic sites. ${ }^{32}$ For similar reasons, CD30 expression is not always reliable in differentiating embryonal carcinoma from solid yolk sac tumor. Even though OCT3/4 is reported to be a more sensitive marker of embryonal carcinoma than CD30, it has recently been reported that up to $24 \%$ of metastatic embryonal carcinomas completely lack both CD30 and OCT3/4 expression post-chemotherapy. ${ }^{33}$ Therefore, SOX2 could potentially be another marker helpful in the distinction of embryonal carcinoma from seminoma, seminoma with early carcinomatous differentiation or solid yolk sac tumor, and deserves further investigation, including that in post-chemotherapy settings.

In addition, we observed SOX2 positivity in the primitive neuroectodermal component of immature teratoma. This finding is not surprising as SOX2 plays an important role in the development of the nervous system and is known to be present in neural stem cells. ${ }^{16,17}$ Recently, Santagata et $a l^{8}$ reported focal SOX2 immunoreactivity in the epithelial components of teratoma. We also observed focal SOX2 and OCT3/4 positivity in the glandular lining of some cases of teratoma. However, on morphological evaluation, these foci showed marked nuclear atypia, akin to embryonal carcinoma (Figure 5). We 


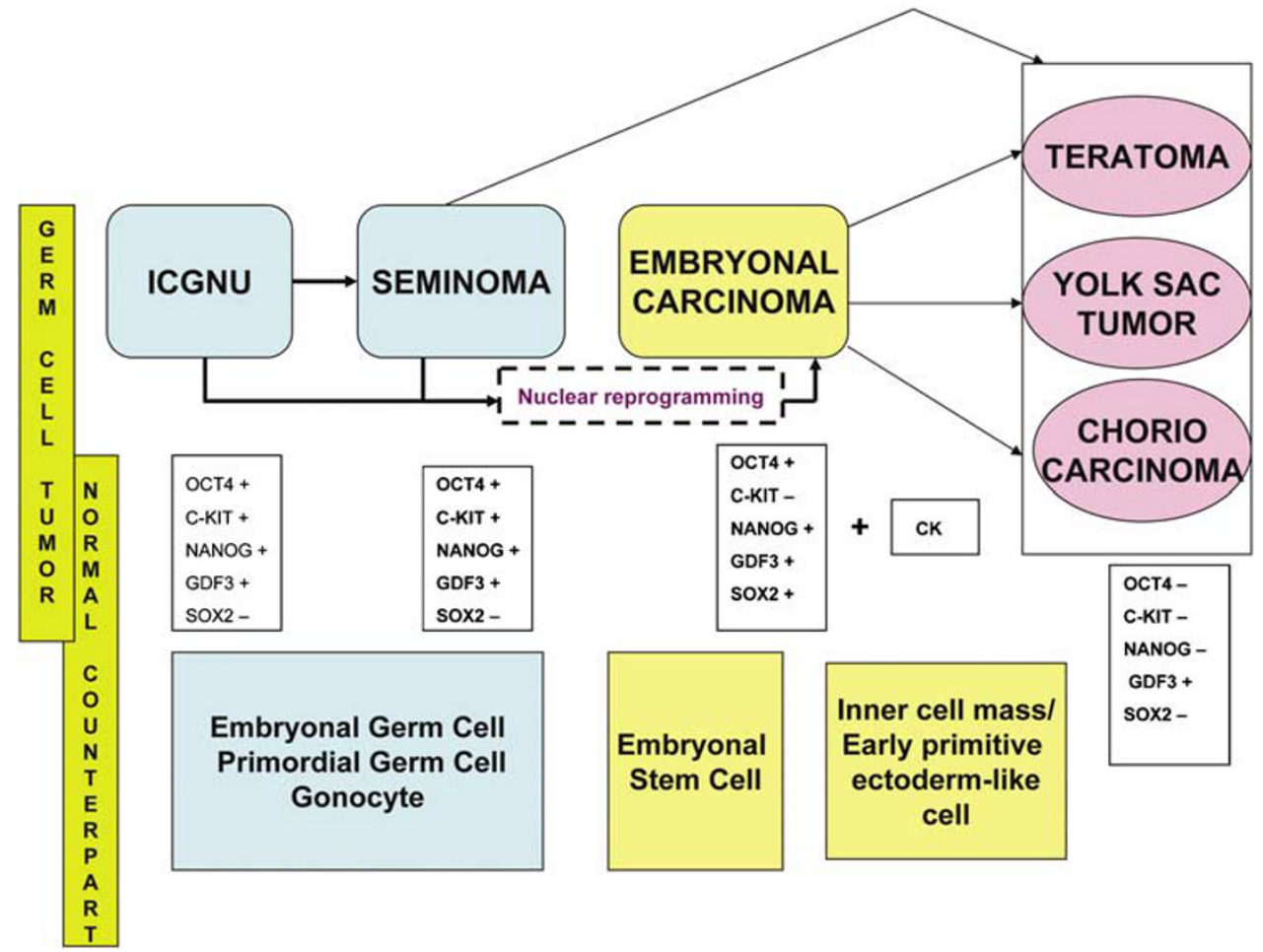

Figure 4 Suggested pathogenesis model for germ cell tumors.
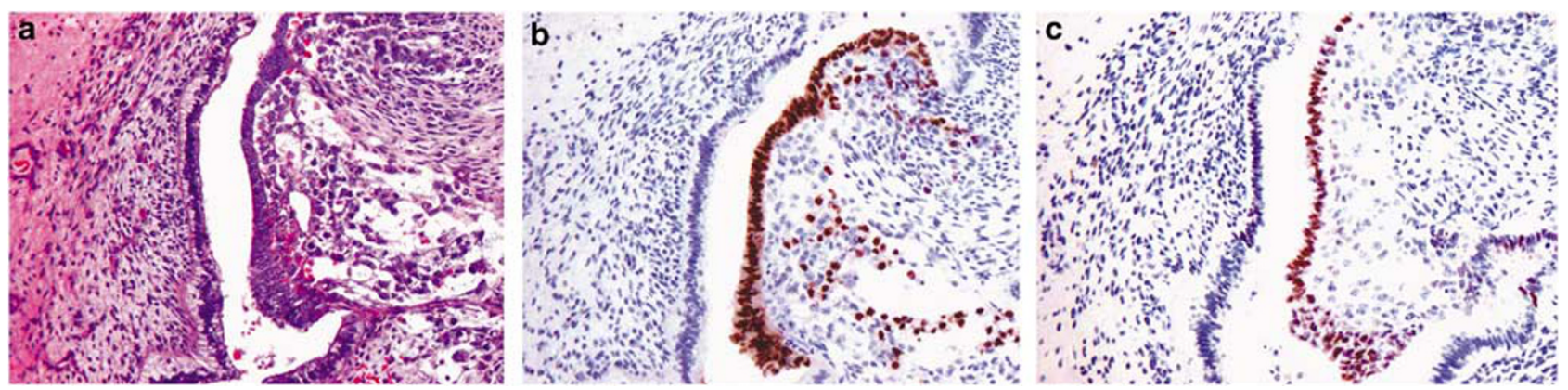

Figure 5 A teratomatous gland with focal embryonal carcinoma-like lining (a). Immunostains for OCT3/4 (b) and SOX2 (c) highlight the embryonal carcinoma nuclei in the lining.

believe that these areas represent residual embryonal carcinoma in the foci that are differentiating toward mature teratoma in mixed germ cell tumors.

Our observation that GDF3 is diffusely positive in yolk sac tumor, and usually only focally positive in embryonal carcinoma can be of additional utility in differentiating solid yolk sac tumor from embryonal carcinoma. Although AFP positivity and OCT3/4 negativity is diagnostic of yolk sac tumor, AFP immunohistochemical staining is generally not a very sensitive marker of yolk sac differentiation, showing positive staining in only $55-75 \%$ of yolk sac tumors. ${ }^{18,20}$ Using RNA protection assays, Caricasole et $a l^{34}$ found abundant GDF3 expressions in the majority of the non-seminomatous tumors, with the highest expression in embryonal carcinoma and yolk sac tumor and low or absent expression in mature and immature teratoma. Korkola et a $1^{9}$ also found that the GDF3 gene was significantly overrepresented in embryonal carcinoma, whereas some seminomas showed detectable but very low expression. On immunohistochemical staining, they observed strong cytoplasmic staining for GDF3 in embryonal carcinoma, with weaker but diffuse (as illustrated in their Supplementary Figures S4d-f) staining in seminoma and IGCNU. To the best of our knowledge, immunohistochemical expression of GDF3 has not been tested on a wide spectrum of germ cell tumors in a large number of cases. Our finding that GDF3 was also expressed in mature teratoma and in cytotrophoblasts reaffirms that GDF and related gene families may also have an equally important role to play later in organogenesis, as has been suggested by some investigators. ${ }^{34,35}$ At the 
same time, the expression of GDF3 in the mature, and not in the immature components of teratoma is somewhat surprising, and needs further investigation. From our results, we believe that strong and diffuse positivity for GDF3 in the right morphological setting and in conjunction with a lack of staining for OCT3/4 and CD30 should aid in the diagnosis of yolk sac tumor.

In summary, we have investigated the immunohistochemical expression pattern and utility of two new stem cell markers in various testicular germ cell tumors. Our results support the prevailing opinion that embryonal carcinoma is closer to the embryonic stem cell than to seminoma or IGCNU. It is likely that seminoma/IGCNU undergo nuclear reprogramming to give rise to embryonal carcinoma cells, a more primitive phenotype than seminoma/IGCNU. We propose that SOX2 may be a useful addition to the immunohistochemical marker panel (along with CD30 and AE1/AE3) for the diagnosis of early carcinomatous differentiation in seminoma. Similarly, positivity for GDF3 in the correct morphological context and absent OCT3/4 immunoreactivity may aid in the diagnosis of yolk sac tumor.

\section{References}

1 Heidenreich A. Clinical stage I nonseminomatous testicular germ-cell tumors: surgery or watchful waiting, still an issue? Curr Opin Urol 2002;12:427-430.

2 Hermans BP, Sweeney CJ, Foster RS, et al. Risk of systemic metastases in clinical stage I nonseminoma germ cell testis tumor managed by retroperitoneal lymph node dissection. J Urol 2000;163:1721-1724.

3 Stephenson AJ, Bosl GJ, Bajorin DF, et al. Retroperitoneal lymph node dissection in patients with low stage testicular cancer with embryonal carcinoma predominance and/or lymphovascular invasion. J Urol 2005;174:557-560.

4 Tickoo SK, Hutchinson B, Bacik J, et al. Testicular seminoma: a clinicopathologic and immunohistochemical study of 105 cases with special reference to seminomas with atypical features. Int J Surg Pathol 2002;10:23-32.

5 Hart AH, Hartley L, Parker K, et al. The pluripotency homeobox gene NANOG is expressed in human germ cell tumors. Cancer 2005;104:2092-2098.

6 Jones TD, Ulbright TM, Eble JN, et al. OCT4 staining in testicular tumors: a sensitive and specific marker for seminoma and embryonal carcinoma. Am J Surg Pathol 2004;28:935-940.

7 Tai MH, Chang CC, Kiupel M, et al. Oct4 expression in adult human stem cells: evidence in support of the stem cell theory of carcinogenesis. Carcinogenesis 2005;26:495-502.

8 Santagata S, Ligon KL, Hornick JL. Embryonic stem cell transcription factor signatures in the diagnosis of primary and metastatic germ cell tumors. Am J Surg Pathol 2007;31:836-845.

9 Korkola JE, Houldsworth J, Chadalavada RS, et al. Down-regulation of stem cell genes, including those in a $200-\mathrm{kb}$ gene cluster at $12 \mathrm{p} 13.31$, is associated with in vivo differentiation of human male germ cell tumors. Cancer Res 2006;66:820-827.

10 Skotheim RI, Lind GE, Monni O, et al. Differentiation of human embryonal carcinomas in vitro and in vivo reveals expression profiles relevant to normal development. Cancer Res 2005;65:5588-5598.

11 Sperger JM, Chen X, Draper JS, et al. Gene expression patterns in human embryonic stem cells and human pluripotent germ cell tumors. Proc Natl Acad Sci USA 2003;100:13350-13355.

12 Rodriguez E, Houldsworth J, Reuter VE, et al. Molecular cytogenetic analysis of i(12p)-negative human male germ cell tumors. Genes Chromosomes Cancer 1993;8:230-236.

13 Miyagi S, Saito T, Mizutani K, et al. The Sox-2 regulatory regions display their activities in two distinct types of multipotent stem cells. Mol Cell Biol 2004;24:4207-4220.

14 Tomioka M, Nishimoto M, Miyagi S, et al. Identification of Sox-2 regulatory region which is under the control of Oct-3/4-Sox-2 complex. Nucleic Acids Res 2002;30:3202-3213.

15 Yuan H, Corbi N, Basilico C, et al. Developmentalspecific activity of the FGF-4 enhancer requires the synergistic action of Sox2 and Oct-3. Genes Dev 1995;19:2635-2645

16 Episkopou V. SOX2 functions in adult neural stem cells. Trends Neurosci 2005;28:219-221.

17 Catena R, Tiveron C, Ronchi A, et al. Conserved POU binding DNA sites in the Sox2 upstream enhancer regulate gene expression in embryonic and neural stem cells. J Biol Chem 2004;279:41846-41857.

18 Emerson RE, Ulbright TM. The use of immunohistochemistry in the differential diagnosis of tumors of the testis and paratestis. Semin Diagn Pathol 2005;22:33-50.

19 Clark AT, Rodriguez RT, Bodnar MS, et al. Human STELLAR, NANOG, and GDF3 genes are expressed in pluripotent cells and map to chromosome 12p13, a hotspot for teratocarcinoma. Stem Cells 2004;22: 169-179.

20 Ulbright TM AM, Young RH. Tumors of the Testis, Adnexa, Spermatic Cord and Scrotum: Atlas of Tumor Pathology. Third Series, Fascicle 25 Armed Forces Institute of Pathology: Washington, DC, 1999.

21 Honecker F, Oosterhuis JW, Mayer F, et al. New insights into the pathology and molecular biology of human germ cell tumors. World J Urol 2004;22:15-24.

22 Honecker F, Stoop H, Mayer F, et al. Germ cell lineage differentiation in non-seminomatous germ cell tumours. J Pathol 2006;208:395-400.

23 Srigley JR, Mackay B, Toth P, et al. The ultrastructure and histogenesis of male germ neoplasia with emphasis on seminoma with early carcinomatous features. Ultrastruct Pathol 1988;12:67-86.

24 Bredael JJ, Vugrin D, Whitmore Jr WF. Autopsy findings in 154 patients with germ cell tumors of the testis. Cancer 1982;50:548-551.

25 Czaja JT, Ulbright TM. Evidence for the transformation of seminoma to yolk sac tumor, with histogenetic considerations. Am J Clin Pathol 1992;97:468-477.

26 Motzer RJ, Reuter VE, Cordon-Cardo C, et al. Blood group-related antigens in human germ cell tumors. Cancer Res 1988;48:5342-5347.

27 Yuasa T, Yoshiki T, Ogawa O, et al. Detection of alphafetoprotein mRNA in seminoma. J Androl 1999; $20: 336-340$. 
28 Donovan PJ. The germ cell-the mother of all stem cells. Int J Dev Biol 1998;42:1043-1050.

29 Takahashi K, Yamanaka S. Induction of pluripotent stem cells from mouse embryonic and adult fibroblast cultures by defined factors. Cell 2006;126: 663-676.

30 Rathjen J, Lake JA, Bettess MD, et al. Formation of a primitive ectoderm like cell population, EPL cells, from ES cells in response to biologically derived factors. J Cell Sci 1999;112:601-612.

31 Ginsburg M, Snow MH, McLaren A. Primordial germ cells in the mouse embryo during gastrulation. Development 1990;110:521-528.

32 Berney DM, Shamash J, Pieroni K, et al. Loss of CD30 expression in metastatic embryonal carcinoma: the effects of chemotherapy? Histopathology 2001;39: 382-385.

33 Sung MT, Jones TD, Beck SD, et al. OCT4 is superior to CD30 in the diagnosis of metastatic embryonal carcinomas after chemotherapy. Hum Pathol 2006; 37:662-667.

34 Caricasole AA, van Schaik RH, Zeinstra LM, et al. Human growth-differentiation factor 3 (hGDF3): developmental regulation in human teratocarcinoma cell lines and expression in primary testicular germ cell tumours. Oncogene 1998;16:95-103.

35 Jones CM, Simon-Chazottes D, Guenet JL, et al. Isolation of Vgr-2, a novel member of the transforming growth factor-beta-related gene family. Mol Endocrinol 1992;6:1961-1968. 